\title{
Low Survival Rates of Oral and Oropharyngeal Squamous Cell Carcinoma
}

\author{
Anna Carolina Omena Vasconcellos Le Campion,, Camila Maria Beder Ribeiro,, \\ Ronir Raggio Luiz, ${ }^{3}$ Francisco Feliciano da Silva Júnior, ${ }^{1}$ \\ Herbert Charles Silva Barros, ${ }^{4}$ Karine de Cássia Batista dos Santos, ${ }^{1}$ \\ Stefania Jeronimo Ferreira, ${ }^{1}$ Lucio Souza Gonçalves, ${ }^{5}$ and Sonia Maria Soares Ferreira ${ }^{1,2}$ \\ ${ }^{1}$ CESMAC University Center, Maceió, AL, Brazil \\ ${ }^{2}$ Federal University of Alagoas, Maceió, AL, Brazil \\ ${ }^{3}$ Federal University of Rio de Janeiro, Rio de Janeiro, RJ, Brazil \\ ${ }^{4}$ State Secretary of Health (SESAU), Alagoas, Brazil \\ ${ }^{5}$ Post-Graduate Program in Dentistry, Estácio de Sá University, Rio de Janeiro, RJ, Brazil \\ Correspondence should be addressed to Sonia Maria Soares Ferreira; sonia.ferreira@cesmac.edu.br
}

Received 2 February 2017; Revised 3 April 2017; Accepted 27 April 2017; Published 30 May 2017

Academic Editor: Gilberto Sammartino

Copyright (C) 2017 Anna Carolina Omena Vasconcellos Le Campion et al. This is an open access article distributed under the Creative Commons Attribution License, which permits unrestricted use, distribution, and reproduction in any medium, provided the original work is properly cited.

\begin{abstract}
Aim. To assess the epidemiological and clinical factors that influence the prognosis of oral and oropharyngeal squamous cell carcinoma (SCC). Methods. One hundred and twenty-one cases of oral and oropharyngeal SCC were selected. The survival curves for each variable were estimated using the Kaplan-Meier method. The Cox regression model was applied to assess the effect of the variables on survival. Results. Cancers at an advanced stage were observed in 103 patients (85.1\%). Cancers on the tongue were more frequent $(23.1 \%)$. The survival analysis was $59.9 \%$ in one year, $40.7 \%$ in two years, and $27.8 \%$ in 5 years. There was a significant low survival rate linked to alcohol intake ( $p=0.038)$, advanced cancer staging ( $p=0.003)$, and procedures without surgery $(p<0.001)$. When these variables were included in the Cox regression model only surgery procedures $(p=0.005)$ demonstrated a significant effect on survival. Conclusion. The findings suggest that patients who underwent surgery had a greater survival rate compared with those that did not. The low survival rates and the high percentage of patients diagnosed at advanced stages demonstrate that oral and oropharyngeal cancer patients should receive more attention.
\end{abstract}

\section{Introduction}

The incidence of oral cancer in Brazil has been estimated at around 15,290 new cases per year, putting oral cancer into the seventh position of all malignant neoplasia [1]. Among several histological types of oral neoplasia, the squamous cell carcinoma (SCC) is the more frequent, representing $90 \%$ of all cases of oral cancer [2].

Cancer is primarily a disease caused by genetic changes that progress as sequential series of somatic mutations in specific genes such as protooncogenes and tumor suppressor genes, resulting in uncontrolled cancerous cell proliferation $[3,4]$. These events can be triggered by extrinsic and/or intrinsic factors, such as lifestyle, environmental, immunosuppression, and individual susceptibility $[5,6]$. Among the extrinsic factors, tobacco use and alcohol intake represent the highest risk to the emergence of this malignant disease $[7,8]$.

Studies have shown that low social and economic status and deprivation are significantly associated with an increased risk of oral cancer $[9,10]$.

The primary location of oral cancer is an important prognostic factor because the affected anatomic area can determine the accessibility and extension of surgery [11]. In addition, it can define the necessity of additional therapeutic procedures, such as the prophylactic cervical ganglionectomy as well as radiotherapy and adjuvant chemotherapy [12]. 
Almost half of the cases of oral cancer worldwide have been diagnosed in stages III and IV $[13,14]$. Early diagnosis of oral and oropharyngeal SCC is essential for a good prognosis and therefore dentists play a fundamental role in the early detection and prevention of this type of oral cancer [15].

Oral and oropharyngeal cancer has a survival rate $\leq 50 \%$ after 5 years. However, this time can be increased when the cancers are diagnosed at an early stage [16, 17]. Cancer mortality is influenced by variations in quantity and quality of the available health services, the delay in diagnosis, or diagnoses at advanced stages, beyond the sequelae of treatment [18]. Oral cancer is a public health problem and early diagnosis as well as assurance of appropriated and fast care is required in order to achieve a better quality of life and lower morbidity/mortality for these patients. Thus, the aim of the current study was to assess the influence of epidemiological and clinical factors on the prognostic of oral and oropharyngeal squamous cell carcinoma (SCC) in a group of patients from one referral center in the state of Alagoas, Brazil.

\section{Material and Methods}

One hundred and twenty-one patients diagnosed in a reference service in stomatology as having oral and oropharyngeal squamous cell carcinoma (SCC) and treated in an Oncology High Complexity Center (CACON) (Alagoas, Brazil) were enrolled in the current study. As the inclusion criteria, all patients must be diagnosed and treated only in these two centers. All subjects were informed about the aims, risks, and benefits of the study and signed a consent form. Patients older than 18 years were examined between March 2005 and March 2013. The medical records whose lack of information made the results of the study unfeasible were excluded.

The study protocol was conducted in full accordance with the World Medical Association Declaration of Helsinki and was approved by the Review Committee for Human Subjects of the University Center of Research CESMAC (number 367.585/2013).

2.1. Procedures and Instruments. Epidemiological data (age, gender, skin color, residence, education, and occupation), risk habits (alcohol intake and tobacco use), clinical characteristics, treatment implemented for the oral cancer, date of the diagnosis, date of the last appointment, and date of death were collected from medical records and during the patient's appointments with the examiner.

The date of death was confirmed using the Mortality Information System applying the following filters: patient's name, date of birth, and mother's name. Date of death as well as the underlying cause was searched according to the International Statistical Classification of Diseases and Related Health Problems-10th Revision (ICD-10).

The oral cancers were located on the hard palate, gingiva, anterior two-thirds of tongue, lips, jugal mucosa, floor of mouth, and alveolar and retromolar mucosa, while the oropharyngeal cancers were on the soft palate, tongue base, tonsillar region, uvula, and posterior pharynx [2]. The clinical stage evaluation was carried out according to the Union for International Cancer Control [19].

2.2. Data Analysis. All analyses were performed using the software SPSS ${ }^{\circledR} 20.0$ for Windows (Statistical Package for Social Sciences, IBM, USA). The descriptive analysis included the absolute and relative frequency for categorical variables. Comparison between groups (death and survival) was carried out using the Chi-square test or Fisher's exact test.

For the inferential analysis with the outcome death, the following variables were changed: the anatomical locations of cancers were clustered as oral and oropharyngeal cancers; TNM system was categorized as early stage (I and II) and advanced stage (III and IV); treatment was categorized as no surgery [radiotherapy (RT), chemotherapy (CT), or combination RT/CT] and surgery (surgery alone, surgery + $\mathrm{RT}$, and surgery + RT + CT).

In order to assess the survival, all the deaths during the study were considered outcome. The variables for the survival analysis were age, gender, skin color, occupation, residence, education, tobacco use, alcohol intake, cancer location, cancer staging, and surgery procedures. The survival curve was estimated for each variable using the Kaplan-Meier method. The comparison between curves was obtained by the long-rank test. The Cox regression model was used to assess the effect of the variables on survival (multivariate analysis to calculate hazard ratios), which included variables with the following characteristics according to the Kaplan-Meier analysis: significant difference $(p<0.05)$ and no crossing between curves. The level of significance established for all analyses was $5 \%$.

\section{Results}

3.1. Characteristics of the Study Sample. The sociodemographic and clinical characteristics of the 121 patients who participated in the current study are presented in Table 1. The majority of the patients were male ( $n=81 ; 66.9 \%)$, $>40$ years old $(n=77 ; 63.7 \%$ ), and with white skin color $(n=47 ; 38.8 \%)$. The frequencies of tobacco use and alcohol intake were 111 (91.7\%) and 77 (63.6\%), respectively. Cancers at an advanced stage were observed in 103 patients (85.1\%). Cancers on the tongue were the most frequent $(23.1 \%)$, followed by mouth floor (18.2\%) and hard and soft palate (16.5\%). Of the patients who underwent surgery $(n=22$; $18.2 \%), 59 \%$ were diagnosed in advanced stages (III and IV).

Of the 121 patients, $82(67.8 \%)$ died due to SCC and only one $(1.2 \%)$ was $<40$ years old. The majority $(n=57 ; 69.5 \%)$ were male, illiterate $(n=63 ; 76.8 \%)$, noneconomically active $(n=52 ; 63.4 \%)$, smokers $(n=78 ; 95.1 \%)$, alcohol users $(n=$ $56 ; 68.3 \%)$, with advanced cancer staging $(n=74 ; 90.2 \%)$, and not undergoing any surgical procedures $(n=75 ; 91.5 \%)$. When the sociodemographic and clinical characteristics were compared between dead and alive patients, significant difference was found only in the cancer staging $(p=0.009)$ and surgery procedures $(p<0.001)$ (Table 2$)$.

3.2. Survival Analysis. The survival analysis using KaplanMeier method was $59.9 \%$ in one year, $40.7 \%$ in two years, 
TABLE 1: Sociodemographic and clinical characteristics of the 121 patients.

\begin{tabular}{|c|c|c|}
\hline Variable & $N$ & $\%$ \\
\hline \multicolumn{3}{|l|}{ Age } \\
\hline$<40$ years & 44 & 36.3 \\
\hline 40 to 70 years & 37 & 30.6 \\
\hline$>70$ years & 40 & 33.1 \\
\hline \multicolumn{3}{|l|}{ Gender } \\
\hline Male & 81 & 66.9 \\
\hline Female & 40 & 33.1 \\
\hline \multicolumn{3}{|l|}{ Skin color } \\
\hline White & 47 & 38.8 \\
\hline Brown & 41 & 33.9 \\
\hline Black & 33 & 27.3 \\
\hline \multicolumn{3}{|l|}{ Residence } \\
\hline Urban & 72 & 59.5 \\
\hline Rural & 49 & 40.5 \\
\hline \multicolumn{3}{|l|}{ Education } \\
\hline Illiterate & 87 & 71.9 \\
\hline Literate & 34 & 28.1 \\
\hline \multicolumn{3}{|l|}{ Occupation } \\
\hline Economically active & 48 & 39.7 \\
\hline Noneconomically active & 51 & 42.1 \\
\hline Not informed & 22 & 18.2 \\
\hline \multicolumn{3}{|l|}{ Tobacco use } \\
\hline Yes & 111 & 91.7 \\
\hline No & 10 & 8.3 \\
\hline \multicolumn{3}{|l|}{ Alcohol intake } \\
\hline Yes & 77 & 63.6 \\
\hline No & 44 & 36.4 \\
\hline \multicolumn{3}{|l|}{ Cancer location } \\
\hline Tongue (anterior two-thirds) & 28 & 23.1 \\
\hline Mouth floor & 22 & 18.2 \\
\hline Hard palate & 20 & 16.5 \\
\hline Alveolar ridge & 12 & 9.9 \\
\hline Oropharynx & 12 & 9.9 \\
\hline Other & 27 & 22.4 \\
\hline \multicolumn{3}{|l|}{ Clinical presentation } \\
\hline Ulcer & 76 & 62.8 \\
\hline Nodule & 17 & 14.0 \\
\hline Ulcerative and verrucose & 10 & 8.3 \\
\hline Ulcerated nodules & 06 & 5.0 \\
\hline Not informed & 12 & 9.9 \\
\hline \multicolumn{3}{|l|}{ Cancer staging } \\
\hline Early & 18 & 14.9 \\
\hline Advanced & 103 & 85.1 \\
\hline \multicolumn{3}{|l|}{ Surgery } \\
\hline Yes & 22 & 18.2 \\
\hline No & 99 & 81.8 \\
\hline
\end{tabular}

and $27.8 \%$ in 5 years. The mortality rate of the sample was 3.1/100,000 per year. The mean survival was 1165.7 days (3.2 years) (95\% CI: 940.5-1390.9). The median survival was 515
TABLE 2: Comparison of studied variables between patients with and without death (oral cancer/SCC) after diagnosis of oral and oropharyngeal cancer.

\begin{tabular}{|c|c|c|c|}
\hline \multirow{2}{*}{ Variable } & \multicolumn{2}{|c|}{ Death } & \multirow{2}{*}{$p$ value } \\
\hline & Yes $(N=82)$ & $\mathrm{No}(N=39)$ & \\
\hline \multicolumn{4}{|l|}{$N(\%)$} \\
\hline Age & & & 0.434 \\
\hline$<40$ years & $1(1.2)$ & $2(5.1)$ & \\
\hline 40 to 70 years & $55(67.1)$ & $25(64.1)$ & \\
\hline$>70$ years & $26(31.7)$ & $12(30.8)$ & \\
\hline Gender* & & & 0.384 \\
\hline Female & $25(30.5)$ & $15(38.5)$ & \\
\hline Male & $57(69.5)$ & $24(61.5)$ & \\
\hline Skin color ${ }^{*}$ & & & 0.270 \\
\hline White & $23(28.0)$ & $10(25.6)$ & \\
\hline Brown & $35(42.7)$ & $12(30.8)$ & \\
\hline Black & $24(29.3)$ & $17(43.6)$ & \\
\hline Residence* & & & 0.659 \\
\hline Urban & $35(42.7)$ & $15(38.5)$ & \\
\hline Rural & $47(57.3)$ & $24(61.5)$ & \\
\hline Education* & & & 0.236 \\
\hline Illiterate & $63(76.8)$ & $23(66.7)$ & \\
\hline Literate & $19(23.2)$ & $13(33.3)$ & \\
\hline Occupation* & & & 0,665 \\
\hline EA & $30(36.6)$ & $18(46.2)$ & \\
\hline NEA & $52(63.4)$ & $21(53.8)$ & \\
\hline Tobacco use & & & 0.050 \\
\hline Yes & $78(95.1)$ & $33(84.6)$ & \\
\hline No & $04(4.9)$ & $6(15.4)$ & \\
\hline Alcohol intake & & & 0.123 \\
\hline Yes & $56(68.3)$ & $21(53.8)$ & \\
\hline No & $26(31.7)$ & $18(46.2)$ & \\
\hline Cancer locations & & & 0.334 \\
\hline Oral & $72(87.8)$ & $37(94.9)$ & \\
\hline Oropharynx & $10(12.2)$ & $02(5.1)$ & \\
\hline Cancer stagings & & & 0.009 \\
\hline Early & $08(9.8)$ & $11(28.2)$ & \\
\hline Advanced & $74(90.2)$ & $28(71.8)$ & \\
\hline Surgery & & & $<0.001$ \\
\hline Yes & $07(8.5)$ & $15(38.5)$ & \\
\hline No & 75 (91.5) & $24(61.5)$ & \\
\hline
\end{tabular}

${ }^{*}$ Chi-square test. 'Fisher's exact test. NEA: noneconomically active; EA: economically active.

days (95\% CI: $323.3-703.8$ ); that is, half of the patients had died by 515 days after diagnosis (Figure 1(a)).

The long-rank test demonstrated significant low survival for alcohol intake $(p=0.038)$, advanced cancer staging $(p=0.003)$, and no surgical procedures $(p<0.001)$. The survival probability and respective curve regarding these variables are presented in Figures 1(b)-1(d). In the first year after diagnosis, the survival probabilities were $55.3 \%$ and $68.0 \%$ for alcohol users and non-alcohol users, respectively, while in the fifth year the probabilities were $21.8 \%$ and $37.9 \%$. 


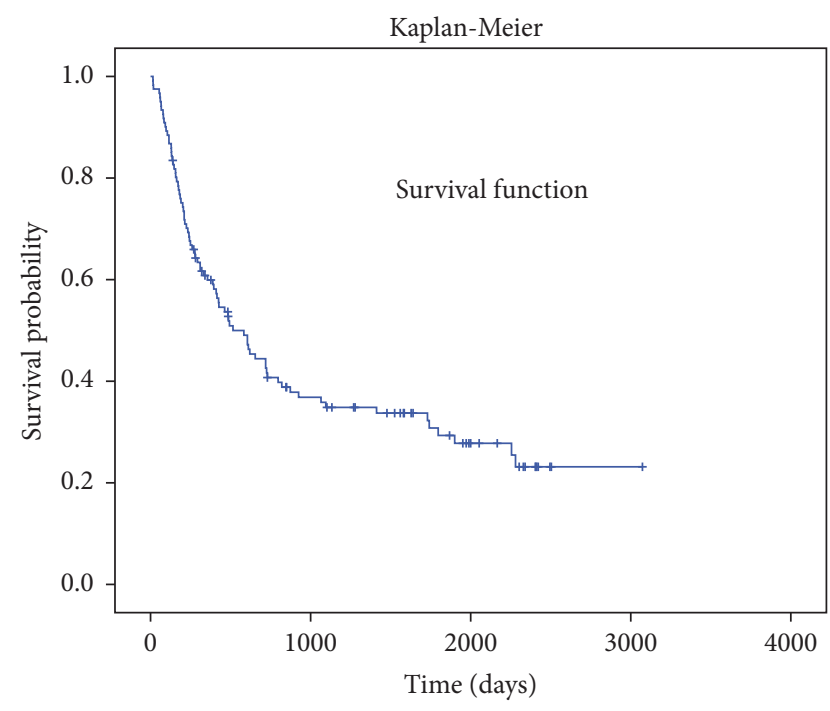

(a)

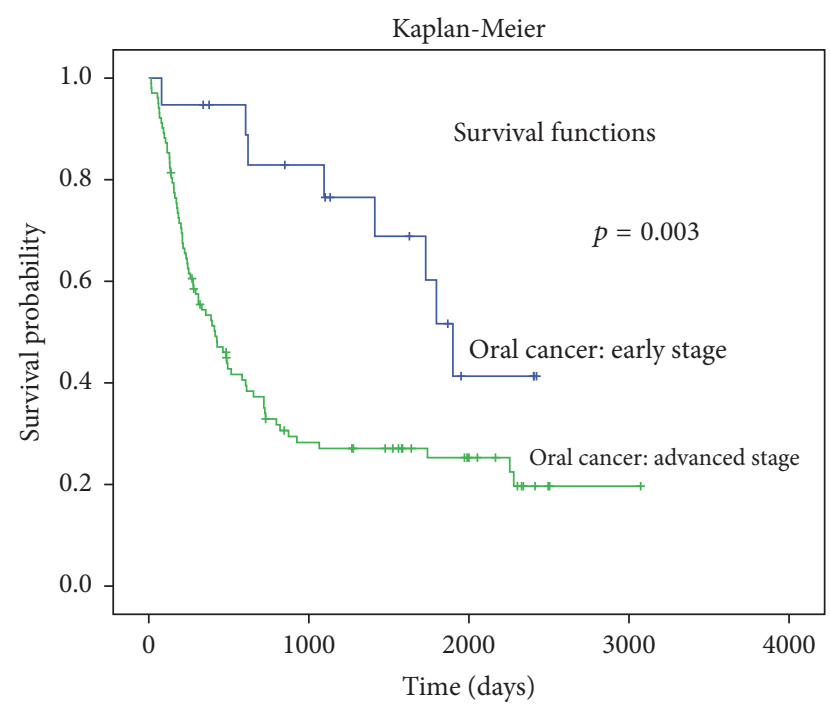

(c)

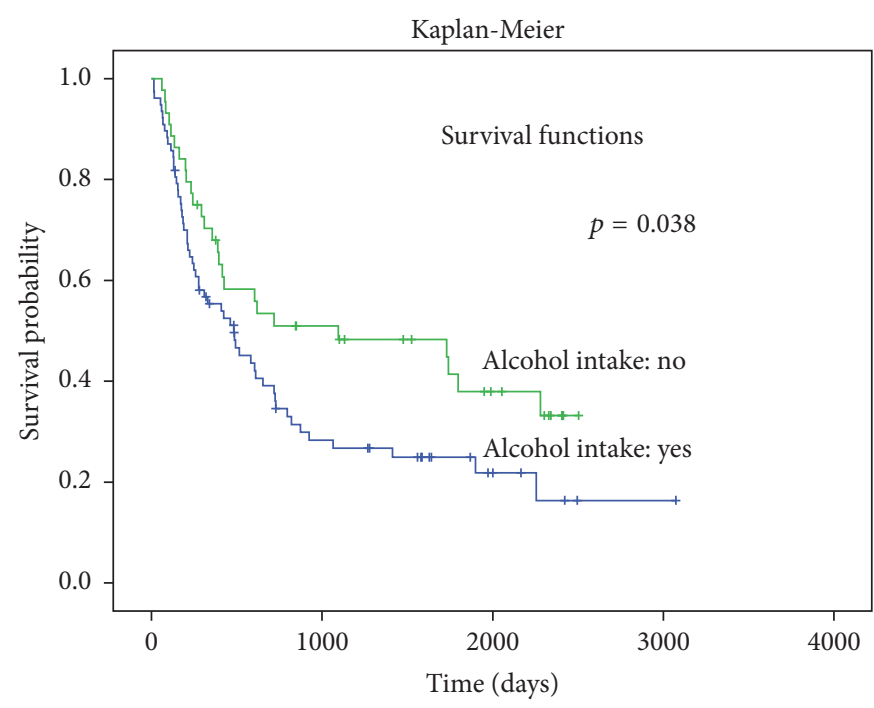

(b)

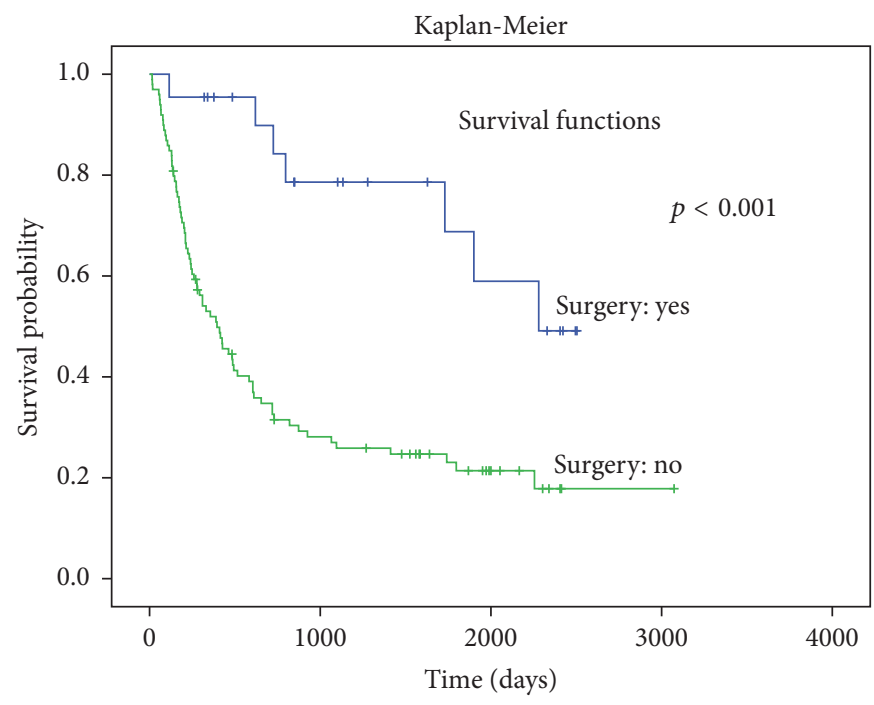

(d)

FiguRE 1: (a) Survival curve of patients with oral and oropharyngeal squamous cell carcinoma estimated by Kaplan-Meier method (Maceió, AL, Brazil, 2005-2013). (b) Survival curve for alcohol intake of patients with oral and oropharyngeal squamous cell carcinoma estimated by Kaplan-Meier method (Maceió, AL, Brazil, 2005-2013). (c) Survival curve for cancer staging of patients with oral and oropharyngeal squamous cell carcinoma estimated by Kaplan-Meier method (Maceió, AL, Brazil, 2005-2013). (d) Survival curve for surgical procedure of patients with oral and oropharyngeal squamous cell carcinoma estimated by Kaplan-Meier method (Maceió, AL, Brazil, 2005-2013).

The median survival was 484 days (95\% CI: 240.1-727.9) for alcohol users and 1095 (95\% CI: 0-2646.8) for non-alcohol users (Figure 1(b)). In the fifth year, the survival probability was $51.6 \%$ and $25.3 \%$ for patients with early stage (I and II) and advanced stage (III and II) of cancer, respectively. The median survival was 1,900 days (95\% CI: 1647.1-2152.9) for early stage of cancer and 415 days (95\% CI: 251.9-578.1) for the advanced stage patients (Figure $1(\mathrm{c})$ ). The death rate was $1.1 / 100,000$ subjects per year for early stage and 3.8/100,000 subjects per year for advanced stage patients.

The survival probability of patients who underwent surgical procedures (associated with chemotherapy, radiotherapy, or both) was $84.2 \%$ (second year) and $59.0 \%$ (fifth year).
On the other hand, the patients that did not receive any surgical procedures presented lower survival probabilities: $31.5 \%$ (second year) and $21.4 \%$ (fifth year) (Figure $1(\mathrm{~d})$ ). The median survival was 2,280 days for the patients who underwent surgery, while for patients that did not receive any surgical procedures the median survival was 395 days (95\% CI: 326.3-703.8).

3.3. Multivariate Analysis. The variables alcohol intake, cancer staging, and surgery were included in the Cox regression model. Of the three variables, only surgical procedures $(p=$ $0.005)$ demonstrated significant effect on the survival. In addition, the outcome of death was 3 times faster for the 
TABLE 3: Cox regression analysis between three variables studied and survival.

\begin{tabular}{lccccc}
\hline Variable & $\beta$ & Standard error & HR & $95 \%$ CI & $p$ value \\
\hline Alcohol intake & 0.29 & 0.25 & 1.34 & $0.83-2.16$ & 0.240 \\
Cancer staging & 0.60 & 0.40 & 1.82 & 3.17 & 0.130 \\
Surgical procedure & 1.15 & 0.41 & $1.41-7.12$ & $\mathbf{0 . 0 0 5}$ \\
\hline
\end{tabular}

$\mathrm{HR}=$ hazard ratio.

patients who did not receive any surgery compared to those that did (Table 3).

\section{Discussion}

Oral cancer is a public health problem and its frequency has increased in recent decades. SCC is the most frequently observed histological cancer type in the mouth and, in virtue of the regional metastasis, has demonstrated a high mortality rate $[1,20]$. In the current study, clinical characteristics, types of treatment, and epidemiological findings were similar to other studies [21-24]. All deaths were caused by oral or oropharyngeal SCC with a frequency (67.8\%) higher than that found by Arriagada et al. [25] in a Chilean population (41.6\%).

In the present study, the percentage of patients diagnosed with oral SCC who survived 5 years $(27.8 \%)$ was similar to Santos et al. [26] (28.4\%) and De Oliveira et al. [27] (24\%); however, it was lower than other studies, such as Bórquez et al. [23] (57\%), Arriagada et al. [25] (58.4\%), Honorato et al. [28] (43.1\%), Montoro et al. [29] (39\%), and De Araújo Daher et al. [30] (38.71\%).

The findings of the current study show that patients in Alagoas with SCC died after a mean of 3.2 years (1165.7 days). The mean survival was higher than the results observed by Honorato et al. [28] (882 days). However, the median survival (515 days) was lower than that found by Miyamoto et al. [31] (930 days) and De Araújo Daher et al. [30] (690 days). Diagnoses in the Northeast region of Brazil are late which leads to cancers with advanced staging, which may favor this low survival rate.

The findings of the present study for cancer staging were similar to other studies. De Araújo Daher et al. [30] demonstrated that survival was better in stage I. After 5 years, the authors observed that the survival rate of the patients with stage II was 59.7\%, stage III $41.6 \%$, and stage IV $23.9 \%$. Santos et al. [32] reported mean survival higher in patients with stage II (10 years), while in stage IV it was 3.7 years. In the study by Bórquez et al. [23], the survival for stages I, II, II, and IV was $86 \%, 67 \%, 52 \%$, and $51 \%$, respectively. These findings confirm the early diagnosis of oral cancer as an important step in increasing survival rates. In addition, the early treatment of a primary neoplasm reduces the mortality, notably before its dissemination. Oral SCC has a high rate of cure (around 80\%) up to the fifth year with stage I of the disease (T1N0), whereas with stage IV it is only $20 \%[16,33]$. Therefore, the prevention of oral cancer, earlier diagnosis, and active treatment of early stage disease may be the best means of improving 5-year survival rates and quality of life after treatment. Achieving these goals may require the enforcement of public education and social efforts relevant to early diagnosis through regular oral examinations by expert clinicians [34].

Surgical treatment is the preferred method for radical treatment, and neck dissection can be performed simultaneously when there is a suspicion of neck lymph node metastasis. In cases of early stage disease where there is no neck metastasis, a single-modality surgical treatment or radiotherapy is appropriate [35].

The present study demonstrated that patients submitted to surgical treatment had a higher survival rate. In the study of Honorato et al. [28] there were a number of similarities with the findings observed here, such as the relevance of surgical treatment, as well as the absence of affected lymph nodes at the moment of diagnosis as a condition necessary for longer survival. In the study of Shan and Gil [35], complete resection of the lesion had the best results in early stage oral cancer. In advanced oral cancer, there was no significant difference between chemotherapy and/or radiotherapy and surgery in terms of 5-year survival rates. However, functional and aesthetic defects that result from radical surgery can reduce a patient's quality of life. Therefore, conservative methods are preferred over radical treatment in older patients.

There is no significant difference between the cancer location and survival in the current study and similar results were observed by De Oliveira et al. [27] However, Arriagada et al. [25] demonstrated a higher survival rate for patients who had cancer in the lower inferior lip when compared with other oral regions. Moreover, for De Araújo Daher et al. [30] the percentage of death was higher in cancers diagnosed in the oropharynx (73.7\%) than in an oral location (50.8\%), suggesting the possibility that SCC that take place in the posterior anatomic location can go unnoticed for a longer time, delaying the diagnosis. Honorato et al. [28] showed that cancers located in the hard palate and jugal mucosa presented the worst prognosis. Thus, there is a disagreement with respect to the localization of the oral neoplasm and the prognosis.

In the present study, there was no association between survival and the variables gender, ethnicity, and tobacco use, after Kaplan-Meier analysis. These findings are similar to those observed by Honorato et al. [28] On the other hand other authors have found associations between survival and different variables. For instance, Miyamoto et al. [31] performed a multivariate analysis and observed an association of advanced cancer (HR 2.5) and RT and CT (HR 4.1) with survival. Montoro et al. [29] reported that the cervical metastasis from oral SCC and inadequate surgical margins affected the survival of patients. In a retrospective study, 
Matos et al. [36] assessed 57 patients diagnosed with oral SCC (except in lips) and found that tumoral thickness $>10 \mathrm{~mm}$ represents an independent risk factor for early progression of oral SCC after surgical treatment.

The epidemiological findings with respect to the deaths were similar to those found by Santos et al. [32]. These authors evaluated the profile of the patients who died between 2000 and 2009 in Aracaju (Capital of Sergipe state, Brazil) and observed that majority of the deaths (seventy-eight) were males, 50-60 years old, with brown skin color, with low education, and from neighborhoods with low quality of life. In the current study, the comparison between survival and nonsurvival groups demonstrated significant difference for cancer staging $(p=0.009)$ and surgical procedures $(p<$ $0.001)$. The findings showed a high likelihood of death in patients with advanced cancer staging and without surgical treatment. In the multivariate model, the risk factor was confirmed only for the absence of surgical procedures ( $p=$ 0.005). However, Honorato et al. [28] observed association of death with other variables, such as ethnicity $(p=0.033)$, cancer located in the lower gingiva $(p=0.048)$, and treatment $(p<0.0001)$. On the present study surgical treatment increased survival even in the advanced stages. Better 5-year survival rate with patients who underwent surgery was reported also in other studies $[28,37]$ evidencing greater survival in those patients undergoing this procedure.

\section{Conclusion}

The low survival rates and the large percentage of patients with an advanced cancer staging diagnosis, as well as the findings that showed an improved survival of those patients who underwent surgery, reinforce the need for greater attention to be paid to oral and oropharyngeal cancer, especially among high-risk populations (elderly, smokers, and alcohol users). In order to increase the 5-year survival rate of oral and oropharyngeal carcinoma, it may be necessary to improve public education and social efforts relevant to early diagnosis.

\section{Conflicts of Interest}

The authors declare that they have no conflicts of interest.

\section{Acknowledgments}

This study was supported by Department of Science and Technology, Ministry of Health (DECIT/SCTIE/MS), National Council for Scientific and Technological Development $(\mathrm{CNPq})$, Foundation for Research Financial Support in the State of Alagoas (FAPEAL), State Secretary of Health (SESAU) (Alagoas, Brazil), and Municipal Secretary of Health in Maceió, AL (Alagoas, Brazil). The manuscript originated from the Research Program for SUS (PPSUS) no. $60030000713 / 2013$.

\section{References}

[1] Instituto Nacional do Câncer (INCA), Incidência de Câncer no Brasil, Estimativa 2014, INCA, Brasília, 2014.
[2] B. Neville, D. D. Damm, and C. M. Allen, Oral and Maxillofacial Pathology, Elsevier, St. Louis, 3rd edition, 2009.

[3] Z. Wang, C. Wang, Z. Zhao et al., "Association between $-251 \mathrm{~A}>\mathrm{T}$ polymorphism in the interleukin-8 gene and oral cancer risk: a meta-analysis," Gene, vol. 522, no. 2, pp. 168-176, 2013.

[4] W. Li, J. Chen, and C. Liu, "Glutathione S-transferase P1 Ile105Val polymorphism and oral cancer risk: a meta-analysis," International Journal of Medical Sciences, vol. 10, no. 4, pp. 392398, 2013.

[5] S. Petti, "Lifestyle risk factors for oral cancer," Oral Oncology, vol. 45, no. 4-5, pp. 340-350, 2009.

[6] S. Warnakulasuriya, "Causes of oral cancer-an appraisal of controversies," British Dental Journal, vol. 207, no. 10, pp. 471475, 2009.

[7] I. Hindle, M. C. Downer, D. R. Moles, and P. M. Speight, "Is alcohol responsible for more intra-oral cancer?" Oral Oncology, vol. 36, no. 4, pp. 328-333, 2000.

[8] J. L. Ferreira Antunes, T. N. Toporcov, M. G. H. Biazevic, A. F. Boing, C. Scully, and S. Petti, "Joint and independent effects of alcohol drinking and tobacco smoking on oral cancer: a large case-control study," PLoS ONE, vol. 8, no. 7, Article ID e68132, 2013.

[9] D. I. Conway, M. Petticrew, H. Marlborough, J. Berthiller, M. Hashibe, and L. M. D. Macpherson, "Socioeconomic inequalities and oral cancer risk: a systematic review and meta-analysis of case-control studies," International Journal of Cancer, vol. 122, no. 12, pp. 2811-2819, 2008.

[10] M. A. F. Ferreira, M. N. Gomes, F. A. S. Michels, A. A. Dantas, and M. D. R. D. D. O. Latorre, "Social inequality in morbidity and mortality from oral and oropharyngeal cancer in the city of São Paulo, Brazil: 1997-2008," Cadernos de Saude Publica, vol. 28, no. 9, pp. 1663-1673, 2012.

[11] F. C. S. A. Almeida, C. Cazal, F. D. Nunes, M. E. Araújo, R. B. Dias, and D. P. Silva, "Prognostic factors in oral cancer," Rev Bras Cienc Saude, vol. 15, no. 4, pp. 471-478, 2011.

[12] K.-H. Fan, C.-Y. Lin, C.-J. Kang et al., "Combined-modality treatment for advanced oral tongue squamous cell carcinoma," International Journal of Radiation Oncology Biology Physics, vol. 67, no. 2, pp. 453-461, 2007.

[13] S. Warnakulasuriya, "Global epidemiology of oral and oropharyngeal cancer," Oral Oncology, vol. 45, no. 4-5, pp. 309-316, 2009.

[14] P. Güneri and J. B. Epstein, "Late stage diagnosis of oral cancer: components and possible solutions," Oral Oncology, vol. 50, no. 12, pp. 1131-1136, 2014.

[15] N. Akbulut, B. Oztas, S. Kursun, and S. Evirgen, "Delayed diagnosis of oral squamous cell carcinoma: a case series," Journal of Medical Case Reports, vol. 5, article 291, 2011.

[16] S. N. Rogers, J. S. Brown, J. A. Woolgar et al., "Survival following primary surgery for oral cancer," Oral Oncology, vol. 45, no. 3, pp. 201-211, 2009, http://dx.doi.

[17] L. P. Kowalski, A. L. Carvalho, A. V. Martins Priante, and J. Magrin, "Predictive factors for distant metastasis from oral and oropharyngeal squamous cell carcinoma," Oral Oncology, vol. 41, no. 5, pp. 534-541, 2005.

[18] M. G. H. Biazevic, R. A. Castellanos, J. L. F. Antunes, and E. Michel-Crosato, "Trends in oral cancer mortality in the city of São Paulo, Brazil, 1980-2002," Cad Saude Publica, vol. 22, no. 10, pp. 2105-2114, 2006. 
[19] L. H. Sobin, M. K. Gospodarowicz, and C. Wittekind, Union for International Cancer Control-UICC, Wiley-Liss, 7th edition.

[20] S. Warnakulasuriya, "Living with oral cancer: epidemiology with particular reference to prevalence and life-style changes that influence survival," Oral Oncology, vol. 46, no. 6, pp. 407410, 2010

[21] L. C. O. dos Santos, O. de Medeiros Batista, and M. C. T. Cangussu, "Characterization of oral cancer diagnostic delay in the state of Alagoas," Brazilian Journal of Otorhinolaryngology, vol. 76, no. 4, pp. 416-422, 2010.

[22] A. L. R. O. Aui, H. M. Tanimoto, C. D. S. Queiroz et al., "Oral and oropharynges neoplasm-a transversal study in Pio XII Foundation-Cancer Hospital of Barretos," Rev Odontol UNESP, vol. 41, no. 4, pp. 273-280, 2012.

[23] P. Bórquez, F. Capdeville, A. Madrid, M. Veloso, and M. Cßrcamo, "Analysis of survival of 137 patients with oral cancer," Rev Chil Cir, vol. 63, no. 4, pp. 351-355, 2011.

[24] L. G. Ferraz, E. Fávero, A. S. Franzi, A. Rapoport, and A. O. Curioni, "Relationship between the clinical (TNM) and histopathological (pTNM) staging with survival in advanced squamous cell carcinoma of the mouth and oropharynx," Revista Brasileira de Cirurgia de Cabeça e Pescoço, vol. 39, pp. 48-56, 2010.

[25] O. C. Arriagada, B. R. Venegas, M. L. Cantín, D. M. Zavando, C. D. Manterola, and I. G. Suazo, "Oral squamous cell carcinoma: retrospective analysis of 36 cases.," Revista chilena de cirugía, vol. 62, pp. 441-448, 2010.

[26] M. A. Santos, C. C. Danesi, and B. H. Pinheiro, "Relationship between survival of patients with squamous cell carcinoma of the oral cavity and pathological staging, operated at the University Hospital of the Federal University of Santa RS.Maria," Revista Brasileira de Cirurgia de Cabeça e Pescoço, vol. 43, no. 1, pp. 23-28, 2014.

[27] L. R. De Oliveira, A. Ribeiro-Silva, and S. Zucoloto, "Incidence and survival profile of patients with oral squamous cell carcinoma in a Brazilian population," Jornal Brasileiro de Patologia e Medicina Laboratorial, vol. 42, no. 5, pp. 385-392, 2006.

[28] J. Honorato, D. R. Camisasca, L. E. Silva, F. L. Dias, P. A. S. Faria, and S. Q. C. Lourenço, "Overall survival analysis in oral squamous cell carcinoma patients diagnosed at the National Cancer Institute," Revista Brasileira de Epidemiologia, vol. 12, pp. 69-81, 2009.

[29] J. R. D. M. C. Montoro, H. A. Hicz, L. De Souza et al., "Prognostic factors in squamous cell carcinoma of the oral cavity," Brazilian Journal of Otorhinolaryngology, vol. 74, no. 6 , pp. 861-866, 2008.

[30] G. C. De Araújo Daher, G. De Araújo Pereira, and A. C. D. Oliveira, "Epidemiological characteristics of cases of mouth cancer registered in a hospital in the city of uberaba from 1999-2003: a warning toward the need for early diagnosis," Revista Brasileira de Epidemiologia, vol. 11, no. 4, pp. 584-596, 2008.

[31] K. N. Miyamoto, R. F. Bruhn, D. S. Rosa, F. A. Capelli, and J. L. Kanda, "Treatment of oropharyngeal squamous cell cancer with chemotherapy and radiotherapy.Rev Bras Cir Cabeça e Pescoço," in Kanda JL. Treatment of oropharyngeal squamous cell cancer with chemotherapy and radiotherapy.Rev Bras Cir Cabeça e Pescoço, p. 43, 43, 1-5, 2014.

[32] V. T. G. Santos, V. S. Santos, R. A. S. Cravalho, S. A. G. Guedes, and C. L. Trento, "Mortality from oral cancer in Aracaju/SE," in Aracaju/SE, vol. 42, pp. 204-210, Rev Odontol UNESP, Brazil, 2013.
[33] I. van der Waal, R. de Bree, R. Brakenhoff, and J.-W. Coebergh, "Early diagnosis in primary oral cancer: is it possible?" Medicina Oral, Patologia Oral y Cirugia Bucal, vol. 16, no. 3, Article ID 16788, pp. e300-e305, 2011.

[34] B. Seo, C. Lee, and J. Kim, "Changes in the management and survival rates of patients with oral cancer: a 30-year singleinstitution study," Journal of Korean Association of Oral Maxillofacial Surgeons, vol. 42, pp. 31-37, 2016.

[35] J. P. Shan and Z. Gil, "Current concepts in management of oral cancer: surgery," Oral Oncology, vol. 45, no. 4-5, pp. 394-401, 2009.

[36] L. L. Matos, F. R. Pinto, M. A. V. Kulcsar et al., "Tumor thickness as an independent risk factor of early recurrence in oral cavity squamous cell carcinoma," Rev Bras Cir Cabeça e Pescoço, vol. 46, pp. 6-11, 2014.

[37] D. Geum, Y. Roh, S. Yoon et al., "he impact factors on 5-year survival rate in patients operated with oral cancer," J Korean Assoc Oral Maxillofac Surg, vol. 39, no. 5, pp. 207-216, 2013. 


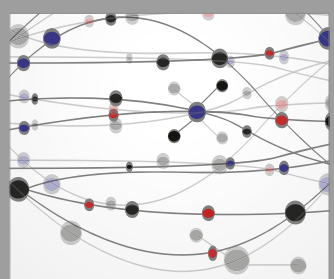

The Scientific World Journal
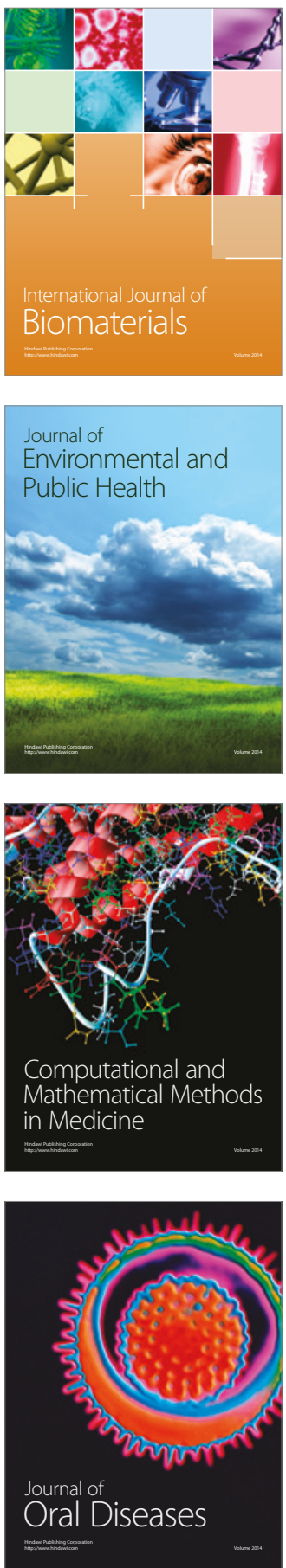
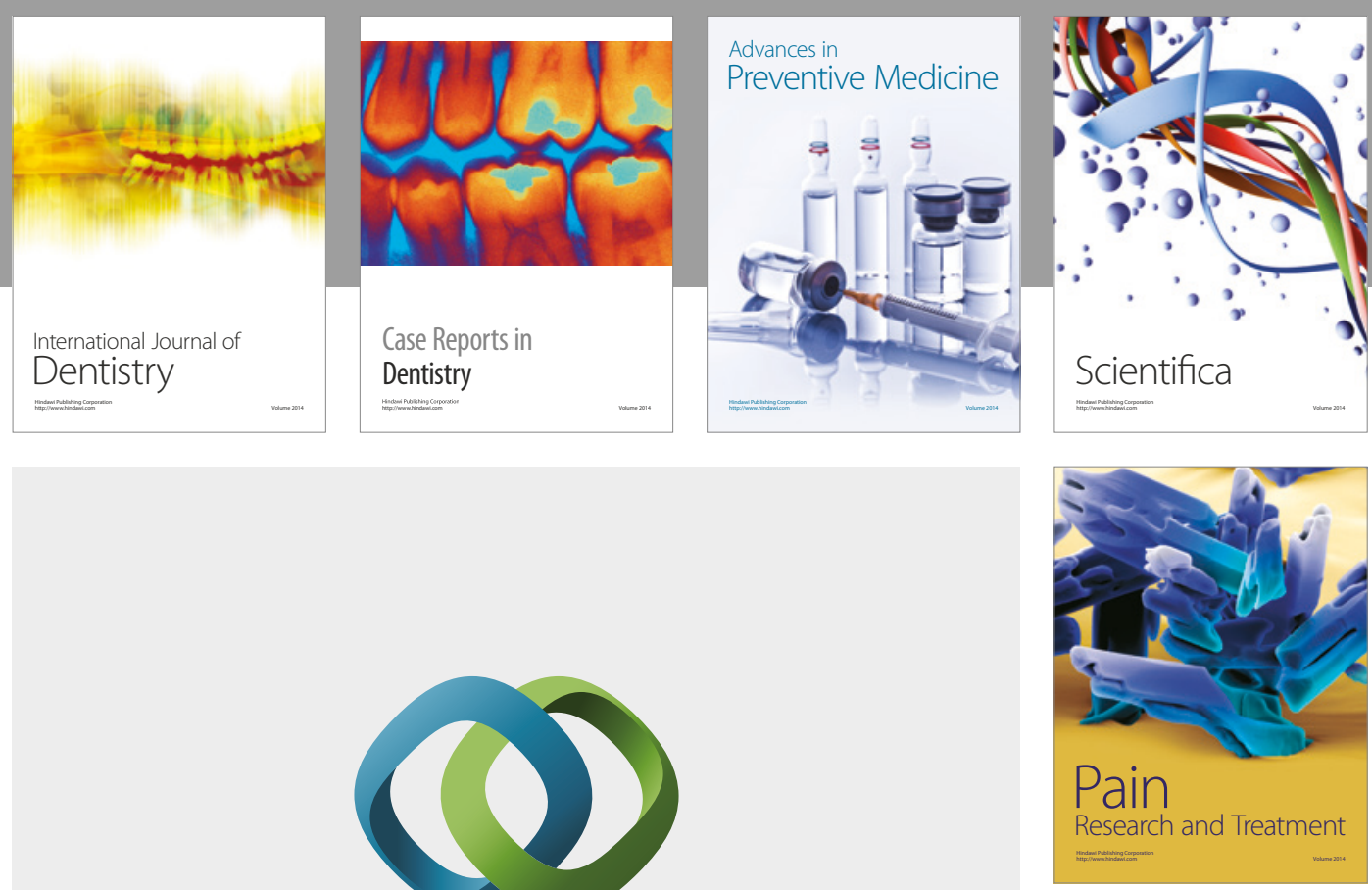

\section{Hindawi}

Submit your manuscripts at

https://www.hindawi.com
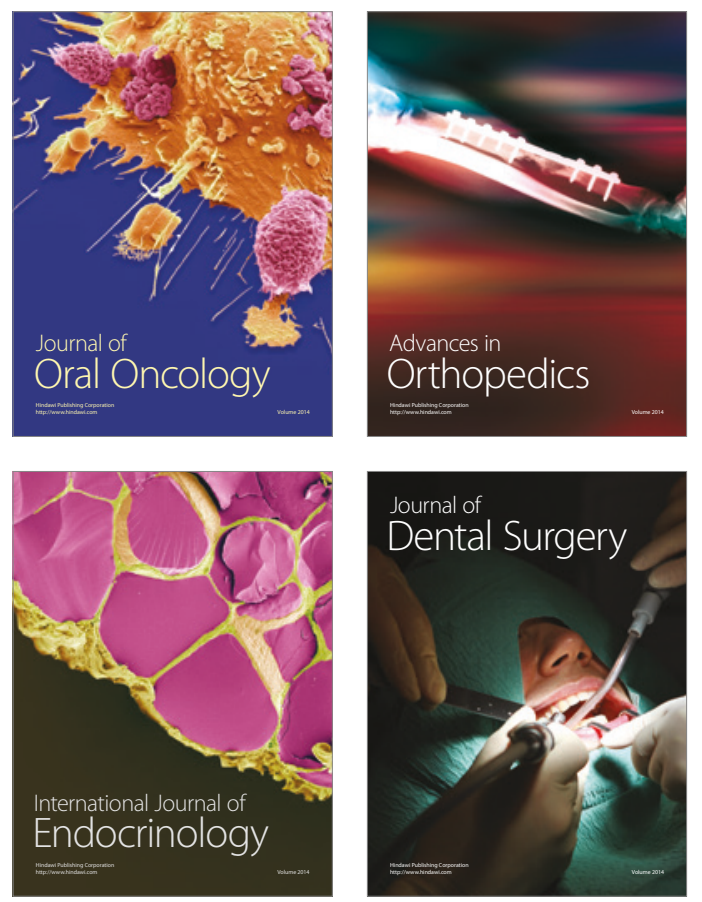
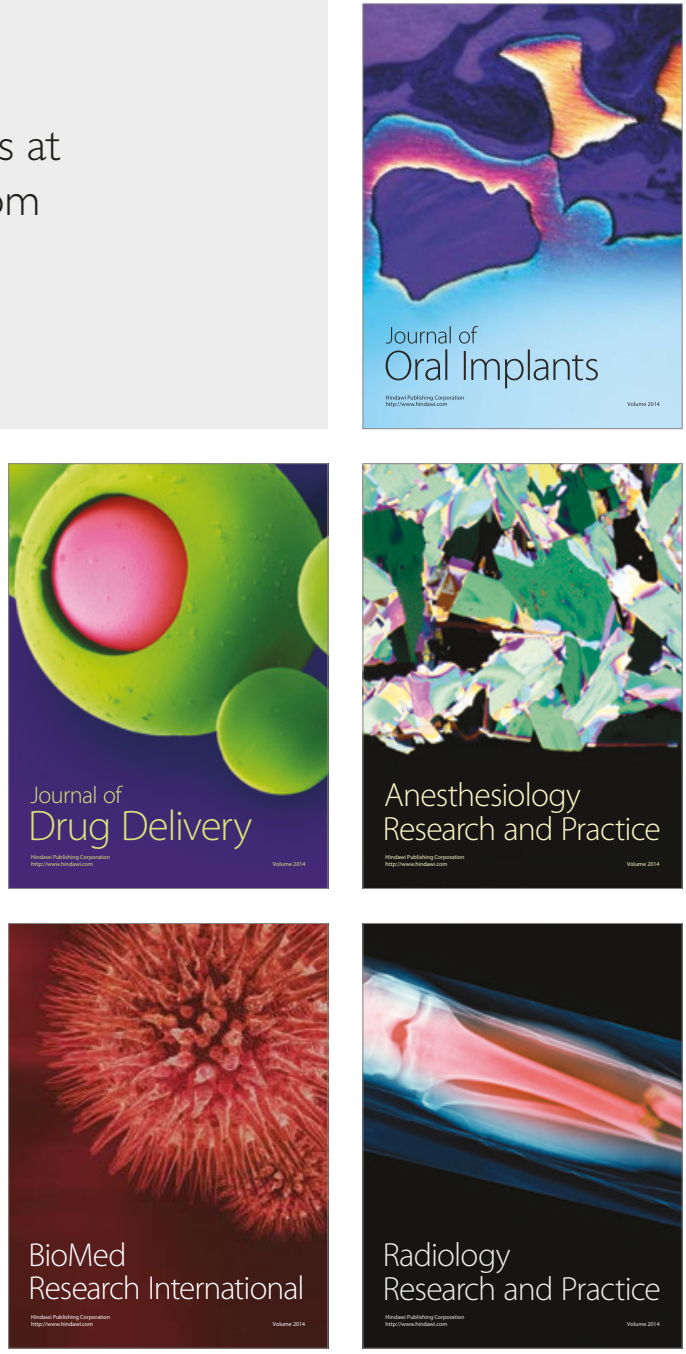